Article

\title{
Low Temperature Synthesis of Lithium-Doped Nanocrystalline Diamond Films with Enhanced Field Electron Emission Properties
}

\author{
Kamatchi Jothiramalingam Sankaran ${ }^{1,2, *,+}$ (D), Kalpataru Panda ${ }^{3,+}{ }^{+}$Ping-Yen Hsieh ${ }^{4}$, \\ Paulius Pobedinskas ${ }^{1,2}$, Jeong Young Park ${ }^{3,5}$, Marlies K Van Bael ${ }^{1,2}$, Nyan-Hwa Tai ${ }^{4}$, \\ I-Nan Lin ${ }^{6}$ and Ken Haenen ${ }^{1,2, *(1)}$ \\ 1 Institute for Materials Research (IMO), Hasselt University, 3590 Diepenbeek, Belgium; \\ paulius.pobedinskas@uhasselt.be (P.P.); marlies.vanbael@uhasselt.be (M.K.V.B.) \\ 2 IMOMEC, IMEC vzw, 3590 Diepenbeek, Belgium \\ 3 Center for Nanomaterials and Chemical Reactions, Institute for Basic Science (IBS), Daejeon 34141, Korea; \\ phy.kalpa@gmail.com (K.P.); jeongypark@kaist.ac.kr (J.Y.P.) \\ 4 Department of Materials Science and Engineering, National Tsing Hua University, Hsinchu 30013, Taiwan; \\ qqwweerreewwqq@hotmail.com (P.-Y.H.); nhtai@mx.nthu.edu.tw (N.-H.T.) \\ 5 Graduate School of EEWS, Korea Advanced Institute of Science and Technology (KAIST), \\ Daejeon 34141, Korea \\ 6 Department of Physics, Tamkang University, Tamsui 251, Taiwan; inanlin@mail.tku.edu.tw \\ * Correspondence: sankaran.kamatchi@uhasselt.be (K.J.S.), ken.haenen@uhasselt.be (K.H.); \\ Tel.: +32-11-268-822 (K.J.S. \& K.H.) \\ $\dagger$ These authors contributed equally to this work.
}

Received: 9 August 2018; Accepted: 22 August 2018; Published: 24 August 2018 updates

\begin{abstract}
Low temperature $\left(350{ }^{\circ} \mathrm{C}\right)$ grown conductive nanocrystalline diamond (NCD) films were realized by lithium diffusion from $\mathrm{Cr}$-coated lithium niobate substrates ( $\mathrm{Cr} / \mathrm{LNO}$ ). The NCD/Cr/LNO films showed a low resistivity of $0.01 \Omega \cdot \mathrm{cm}$ and excellent field electron emission characteristics, viz. a low turn-on field of $2.3 \mathrm{~V} / \mu \mathrm{m}$, a high-current density of $11.0 \mathrm{~mA} / \mathrm{cm}^{2}$ (at $4.9 \mathrm{~V} / \mathrm{m}$ ), a large field enhancement factor of 1670 , and a life-time stability of $445 \mathrm{~min}$ (at $3.0 \mathrm{~mA} / \mathrm{cm}^{2}$ ). The low temperature deposition process combined with the excellent electrical characteristics offers a new prospective for applications based on temperature sensitive materials.
\end{abstract}

Keywords: nanocrystalline diamond; lithium; low temperature; field electron emission

\section{Introduction}

Nanocrystalline diamond (NCD) films grown by chemical vapor deposition, possessing unique and advantageous properties such as high hardness, high chemical inertness, and negative electron affinity (NEA), can be a good candidate for device applications [1,2]. Despite these marvelous properties, the absence of highly conducting NCD confines the potential for the use of this material in electron emission devices. Fortunately, doping NCD with $p$-type (e.g., boron) [3] or $n$-type (e.g., nitrogen, phosphorus etc.) $[4,5]$ dopants can render the films conductive. Particularly, $n$-type doped NCD films reveal highly efficient field electron emission (FEE) characteristics compared to the $p$-type ones [3,6]. Nevertheless, a high-substrate growth temperature of above $800^{\circ} \mathrm{C}$ is required to stimulate the $n$-type doping process, especially when nitrogen and phosphorus are used as dopants [4-6], which is not well-suited for the device fabrication processes. Fabrication of highly conducting $n$-type NCD films at low temperature are desired for the development of diamond-based electronics. 
Lithium $(\mathrm{Li})$ is a possible shallow $n$-type dopant, as $\mathrm{Li}$ is anticipated to occupy interstitial sites in the diamond lattice [7]. Nevertheless, the doping of Li into diamond via ion implantation [8], adsorption [9], diffusion [10,11], or addition of $\mathrm{Li}$ to the gas phase during growth $[12,13]$ were not effective for the fabrication of a highly conducting diamond films, and hence the FEE results obtained so far from these films were also not satisfactory [14]. Freestanding ultrananocrystalline diamond (UNCD) films grown directly on lithium niobate (LNO) substrate have been an exception [15]. However, the highly conducting UNCD films thus obtained were very fragile and detached from the substrate easily, avoiding their use for the fabrication of electronic devices.

In this context, a thin chromium (Cr) interlayer was used for maintaining the integrity of NCD films grown on LNO substrates, which served as a possible source of Li doping. Highly-conducting Li-doped NCD films were synthesized at a very low temperature of about $350{ }^{\circ} \mathrm{C}$, and an enhanced FEE behavior and plasma illumination (PI) properties for NCD films were demonstrated. The potential mechanism for the enhanced FEE and PI properties of Li-doped NCD films was discussed based on the investigation using Raman spectroscopy, X-ray photoelectron spectroscopy (XPS), and secondary ion mass spectroscopy (SIMS).

\section{Materials and Methods}

The Y-cut oriented LNO single crystal substrates $\left(1 \times 1 \mathrm{~cm}^{2}\right.$ in sized; Crystal GmbH, Berlin, Germany) polished to a smoothness of $0.9 \mathrm{~nm}$ were used for growing NCD films. A $50 \mathrm{~nm}$ thick $\mathrm{Cr}$ layer was deposited on the LNO substrates to improve the adhesion between the LNO substrates and the NCD films. The Cr-coating was deposited by a home-built DC-pulsed sputtering system using a radio frequency power of $200 \mathrm{~W}$ in Ar gas for $10 \mathrm{~min}$. The Cr-coated LNO (Cr/LNO) substrates were then nucleated with a water-based state-of-the-art colloidal suspension of ultradispersed detonation diamond (Nano-Carbon Institute Co., Ltd., Nagano, Japan; zeta potential of (45 \pm 5 ) $\mathrm{mV}$ and particle size of 6-7 $\mathrm{nm}$ ) via drop casting and subsequent spin-drying [16]. The growth of $\sim 90 \mathrm{~nm}$ thick NCD layers, designated as $\mathrm{NCD} / \mathrm{Cr} / \mathrm{LNO}$ films, was performed in a linear antenna microwave plasma enhanced chemical vapor deposition (LA CVD) system using plasma containing $10 \%$ methane in hydrogen. The film thickness was monitored by in situ laser reflection interferometry. The microwave power and pressure were $3000 \mathrm{~W}$ and 0.21 Torr, respectively. The substrates were heated up due to the bombardment of the plasma species and the substrate temperature was measured by a single color optical pyrometer with an optical emission coefficient of 0.3 during NCD film deposition. The measured substrate temperature was about $350^{\circ} \mathrm{C}$, which is even lower than the temperature used for the growth of freestanding UNCD films on LNO substrates [15] and is compatible with a Si-device fabrication process. The key necessity for diamond growth at low temperature is a high-plasma density at a low-gas pressure, which leads to a low thermal loading of the substrate materials. While these conditions are not within reach for resonance cavity plasma systems, the LA CVD system enables the deposition of high-quality diamond films on larger areas with satisfactory growth rates, while allowing an easy up-scaling and industrial implementation [17]. To facilitate the comparison, NCD films were also grown on Si-substrates covered with a similar $\mathrm{Cr}$-coating, using the same deposition parameters. The obtained diamond films were designated as NCD/Cr/Si films.

The surface morphology and the crystalline quality of the NCD films were investigated by scanning electron microscopy (SEM; FEI Quanta 200 FEG microscope from ThermoFisher Scientific, Hillsboro, OR, USA), atomic force microscopy (AFM; multi-mode VIII with a Nanoscope V controller from Bruker, Billerica, MA, USA) and micro-Raman spectrum (Horiba Jobin-Yvon T64000 spectrometer, Paris, France; $\lambda=488.0 \mathrm{~nm}$ ). The surface chemical bonding characteristics of the films were investigated by XPS (PHI 1600, Physical Electronics, Chanhassen, MN, USA). Al K $\alpha$ radiation with energy of $1486.74 \mathrm{eV}$ and an energy resolution of $0.47 \mathrm{eV}$ was used as a probe for evaluating the chemical bonding fractions of different phases on the NCD film surfaces. An elemental depth profile analysis of the NCD/Cr/LNO films was carried out using SIMS (TOF-SIMS5, ION-TOF GmbH, bismuth ion source). The resistivity of the NCD films was measured using four-point probe measurements. Room 
temperature FEE properties of NCD films were measured using a tunable parallel-plate setup, in which the anode is a Mo-rod of $3 \mathrm{~mm}$ in diameter and the cathode-to-anode distance " $d$ " was controlled to be around $66 \mu \mathrm{m}$ by a micrometer. The current-voltage characteristics were acquired at a pressure below $10^{-6}$ Torr using a Keithley 237 electrometer.

\section{Results and Discussion}

The featured $\mathrm{NCD} / \mathrm{Cr} / \mathrm{LNO}$ and $\mathrm{NCD} / \mathrm{Cr} / \mathrm{Si}$ films were subjected to four-point probe measurements with the measuring probes directly in contact with the surface of the films to measure the electrical resistivity. It was found that the resistivity $(\rho)$ values of $\mathrm{NCD} / \mathrm{Cr} / \mathrm{LNO}$ and $\mathrm{NCD} / \mathrm{Cr} / \mathrm{Si}$ films were $1 \times 10^{-2}$ and $4.5 \times 10^{3} \Omega \cdot \mathrm{cm}$, respectively, viz. a high conductivity of NCD films was obtained through the use of $\mathrm{Cr} / \mathrm{LNO}$ substrates. Interestingly, the NCD/Cr/LNO films deposited at $350{ }^{\circ} \mathrm{C}$ exhibited low resistivity comparable to that of the freestanding UNCD films grown on LNO substrates $(\rho=1.2 \Omega \cdot \mathrm{cm})[15]$.

Figure 1 shows the FEE properties of the NCD/Cr/LNO films, whereas the inset I of Figure 1 indicates the corresponding Fowler-Nordheim $(\mathrm{F}-\mathrm{N})$ plot. The FEE parameters, including the turn-on field $\left(E_{0}\right)$ and FEE current density $(J)$, were extracted from the $J$-E curves obtained at $d=66 \mu \mathrm{m}$ (Figure 1), where $E$ is the applied field, using the F-N equation [18]. The $E_{0}$ was designated as the point of intersection of the straight lines extrapolated from the low-field and high-field segments of the F-N plots, viz. $\ln \left(J / E^{2}\right)$ versus $1 / E$ curves (inset I, Figure 1$)$. The $E_{0}$ value for inducing the FEE process is around $11.8 \mathrm{~V} / \mu \mathrm{m}$ for $\mathrm{NCD} / \mathrm{Cr} / \mathrm{Si}$ films (curve II, Figure S1a of the supplementary information), whereas the $J$ value is around $6.4 \mathrm{~mA} / \mathrm{cm}^{2}$ at an applied field of $20.0 \mathrm{~V} / \mu \mathrm{m}$. In contrast, the $\mathrm{NCD} / \mathrm{Cr} / \mathrm{LNO}$ films required a much smaller field to turn on the FEE process, i.e., an $E_{0}$ value of $2.3 \mathrm{~V} / \mu \mathrm{m}$ and high $J$ value of $11.0 \mathrm{~mA} / \mathrm{cm}^{2}$ at an applied field of $4.9 \mathrm{~V} / \mu \mathrm{m}$ (Figure 1 ). Moreover, the field enhancement factor $(\beta)$ of the emission sites can be evaluated from the slope $(m)$ of the F-N plot, viz. $m=-\phi^{3 / 2} / \beta$ where $\phi$ is the work function of the diamond materials. The F-N plot in the inset I of Figure 1 shows that the $\beta$ value of the NCD/Cr/LNO films is $\beta_{\mathrm{NCD} / \mathrm{Cr} / \mathrm{LNO}}=1670$, whereas the inset of Figure S1a in the supplementary information indicates that the $\beta$-value of NCD films is $\beta_{\mathrm{NCD} / \mathrm{Cr} / \mathrm{Si}}=980$, revealing a larger field enhancement factor value for the $\mathrm{NCD} / \mathrm{Cr} / \mathrm{LNO}$ films. Moreover, by tuning the cathode-anode separation distance, we characterized the FEE properties of the NCD/Cr/LNO films, in the range $66 \mu \mathrm{m}<d<120 \mu \mathrm{m}$. Figure S1b of the supporting information shows the $J-E$ curves with corresponding F-N plots measured for different $d$ values for NCD/Cr/LNO films. We notice that, as expected, by increasing the distance of the tip from the surface, higher applied field are necessary to extract electrons from NCD/Cr/LNO films. It is to be noted here that $E_{0}$ and $\beta$ values depend on the absolute cathode-anode separation $[19,20]$. 


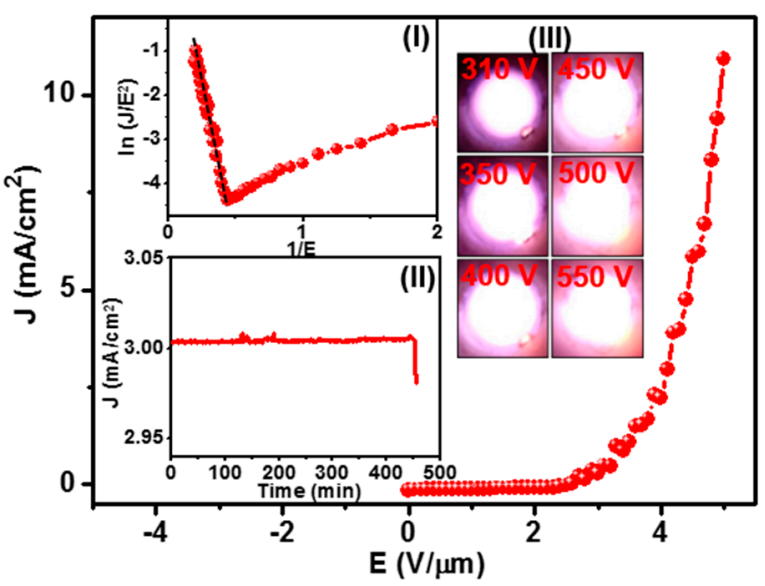

Figure 1. Field electron emission properties (current density-applied field, J-E, curve). Inset I shows the corresponding Fowler-Nordheim (F-N) plot, inset II shows the life-time stability measurement (J-time curve) for NCD films grown on Cr-coated LNO (NCD/Cr/LNO films, while inset III shows the plasma illumination (PI) images versus voltage applied to the microplasma devices using NCD/Cr/LNO films as cathode materials.

Moreover, the life-time $(\tau)$ stability measurements of NCD/Cr/Si and NCD/Cr/LNO films were evaluated by measuring the $J$ versus time curves of these films. Inset II of Figure 1 shows that, ignoring short-term fluctuations owing to adsorption and desorption of residual gas molecules and diffusion of adsorbed species on the emitter surface, the emission current density variations corresponding to $J$ of $3.0 \mathrm{~mA} / \mathrm{cm}^{2}$ were recorded over a period of $445 \mathrm{~min}$ for NCD/Cr/LNO films (at a working field of $4.0 \mathrm{~V} / \mu \mathrm{m}$ ), before the start of degradation. In contrast, the NCD/Cr/Si films show emission current variations recorded for a period of only $215 \mathrm{~min}$ under the same test current density of $3.0 \mathrm{~mA} / \mathrm{cm}^{2}$ (at a working field of $18.9 \mathrm{~V} / \mu \mathrm{m}$ ) (curve II, Figure S1c of supplementary information). Consequently, the $\mathrm{NCD} / \mathrm{Cr} / \mathrm{LNO}$ films exhibit a far more superior FEE behavior, viz., lower $E_{0}$, higher $J$ and longer $\tau$ as compared with the other Li-doped diamond based field emitters reported in the literature, which are summarized in Table $1[14,15]$. Notably, in Table 1, the FEE properties of $\mathrm{NCD} / \mathrm{Si}$ and $\mathrm{NCD} / \mathrm{Cr} / \mathrm{Si}$ films (shown as curves I and II, Figure S1a,c of Supplementary Materials) were included to facilitate the comparison.

Table 1. Comparison of the field electron emission properties of various Li-incorporated diamond based field emitters.

\begin{tabular}{ccccc}
\hline Materials & $\begin{array}{c}\text { Resistivity } \\
\mathbf{(} \cdot \mathbf{c m})\end{array}$ & $\begin{array}{c}\text { Turn-on Field } \\
(\mathbf{V} / \mu \mathbf{m})\end{array}$ & $\begin{array}{c}\text { FEE Current Density } \\
\left(\mathbf{m A} / \mathbf{c m}^{2}\right)\end{array}$ & $\begin{array}{c}\text { Life-Time } \\
(\mathbf{m i n})\end{array}$ \\
\hline Li ion implanted NCD [14] & $9 \times 10^{-2}$ & 10.6 & $25.5 @ 23.2 \mathrm{~V} / \mu \mathrm{m}$ & 1090 \\
Freestanding Li doped UNCD [15] & 1.2 & 4.2 & $0.3 @ 10.0 \mathrm{~V} / \mu \mathrm{m}$ & - \\
NCD/Si [Present study] & $7.1 \times 10^{4}$ & 21.3 & $4.8 @ 35.7 \mathrm{~V} / \mu \mathrm{m}$ & 88 \\
NCD/Cr/Si [Present study] & $4.5 \times 10^{3}$ & 11.8 & $6.4 @ 20.0 \mathrm{~V} / \mu \mathrm{m}$ & 215 \\
NCD/Cr/LNO [Present study] & $1 \times 10^{-2}$ & 2.3 & $11.0 @ 4.9 \mathrm{~V} / \mu \mathrm{m}$ & 445 \\
\hline
\end{tabular}

The SEM image shown in Figure 2a depicts that the NCD/Cr/LNO films have an equi-axed, nano-sized, granular structure. Moreover, Figure $2 \mathrm{~b}$ shows an AFM image taken at ambient conditions along with a histogram (inset, Figure $2 b$ ) indicating that the average grain size of the NCD/Cr/LNO films is around $30 \mathrm{~nm}$ with a very narrow size distribution. The root mean square surface roughness values are ranged between $2-3 \mathrm{~nm}$. The surface morphologies of the NCD/Si and NCD/Cr/Si films are like those of $\mathrm{NCD} / \mathrm{Cr} / \mathrm{LNO}$ films (Figure S2 in supplementary information). It is to be noted that the roughness values were obtained from the raw data without any smoothing or flattening processes. 


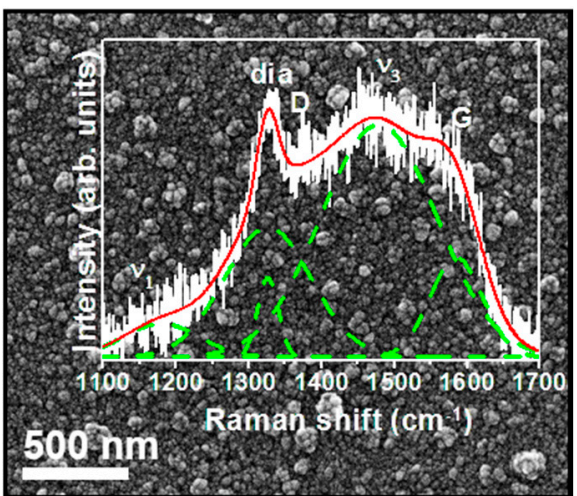

(a)

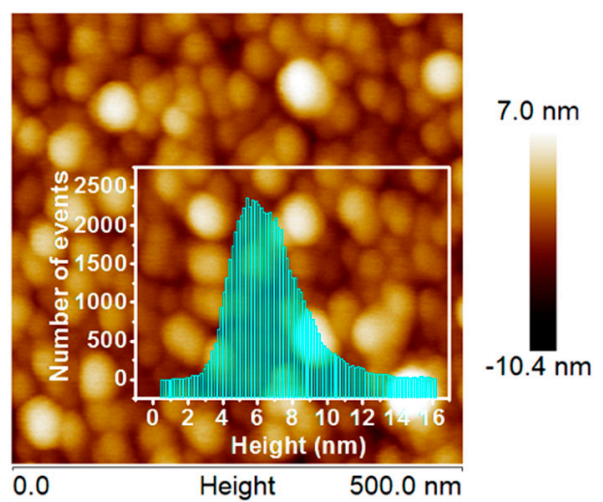

(b)

Figure 2. (a) SEM and (b) AFM micrographs of the NCD/Cr/LNO films, showing a small and uniform grain size distribution in the films. The inset in (a) shows the Raman spectrum $(\lambda=488.0 \mathrm{~nm})$, whereas the inset in (b) shows a histogram for the grain size distribution of the films.

The inset in Figure 2a shows the micro-Raman spectrum of the NCD/Cr/LNO films. Peaks at around $1190 \mathrm{~cm}^{-1}$ and $1470 \mathrm{~cm}^{-1}$ are ascribed to the $v_{1}$ and $v_{3}$-modes of trans-polyacetylene present at the grain boundaries [21]. A sharp peak at $1332 \mathrm{~cm}^{-1}$ corresponds to the $s p^{3}$-bonded carbon ("dia") and a broadened peak at around $1360 \mathrm{~cm}^{-1}$ (D-band) corresponds to disordered carbon. The G-band corresponding to a nanographite phase is observed at around $1540 \mathrm{~cm}^{-1}$ [21]. It should be mentioned that the broadened diamond peak is normally observed for NCD films due to the small diamond grain size which is on the nanometer scale, and the presence of $s p^{2}$ admixtures in the grain boundaries [22,23]. Moreover, the Raman spectrum shows an $I_{\mathrm{D}} / I_{\mathrm{G}}$ ratio of 1.13 , related to the size of the graphite clusters in the NCD films [24], which is higher than that of the $I_{\mathrm{D}} / I_{\mathrm{G}}$ value of $\mathrm{NCD} / \mathrm{Cr} / \mathrm{Si}$ films $\left(I_{\mathrm{D}} / I_{\mathrm{G}}=0.85\right.$, spectrum II, Figure S3 of Supplementary Materials). The increase of the $I_{\mathrm{D}} / I_{\mathrm{G}}$ value implies the formation of nanographite and a decrease in $s p^{3}$ content according to a three stage model of increasing disorder in carbon materials [24,25] (i.e., there is a conversion of $s p^{3}$ to $s p^{2}$ content in NCD/Cr/LNO films as compared with the NCD/Cr/Si films).

The surface bonding characteristics of the NCD films were investigated using XPS. The C1s photoemission spectrum of NCD/Cr/LNO films (Figure S4c in Supplementary Materials) shows that these films contain the $s p^{3} \mathrm{C}-\mathrm{C}$ peak of $35.4 \%$ with $s p^{2} \mathrm{C}=\mathrm{C}$ peak intensity of $53.9 \%$ and $\mathrm{CO} / \mathrm{C}-\mathrm{O}-\mathrm{C}$ peak intensity of $10.7 \%$, respectively. In contrast, for the $\mathrm{NCD} / \mathrm{Cr} / \mathrm{Si}$ films, the $\mathrm{sp}^{3} \mathrm{C}-\mathrm{C}$ peak intensity is around to $47.0 \%$, the $s p^{2} \mathrm{C}=\mathrm{C}$ peak intensity is around to $45.4 \%$, and the $\mathrm{CO} / \mathrm{C}-\mathrm{O}-\mathrm{C}$ peak is around $7.6 \%$ (Figure S4b in Supplementary Materials). There is a larger $s p^{2}$ content for NCD/Cr/LNO films as compared with that for NCD/Cr/Si films. Moreover, the C1s spectrum of NCD/Cr/LNO is shifted towards the low energy side relative to that of the NCD/Si films (Figure S4a in Supplementary Materials) [26], indicating the formation of more nanographitic phases in the NCD/Cr/LNO films.

It is evident through the Raman and XPS studies that there is a more abundant presence of nanographitic phases in the NCD/Cr/LNO films as compared to the NCD/Cr/Si films. The nanographitic phase is located along the grain boundaries of the NCD/Cr/LNO films, which provides conducting paths for the efficient transport of electrons. This is the key factor ensuing in the better conductivity and superior FEE properties for NCD/Cr/LNO films. The question that still remains is what are the roles of the $\mathrm{Li}$ incorporation and the presence of the $\mathrm{Cr}$ interlayer on the enhanced conductivity and FEE behavior of the NCD/Cr/LNO films? For a good field electron emitter, a sufficient electron supplies from the substrate to the emitting sites is very crucial, in addition to the low work function of the emitting surface. The conductivity of the diamond and the resistance of the diamond-to-substrate interface need to be optimized for an efficient supply of electrons. The results described above indicate that the utilization of a $\mathrm{Cr}$ interlayer and incorporation of $\mathrm{Li}$ in NCD films 
fulfill these two critical requirements simultaneously, such that NCD/Cr/LNO films show a low bulk/interfacial resistivity leading to enhanced FEE properties. To understand the genuine factor enhancing these properties, the elemental depth profile analysis of the NCD/Cr/LNO films was carried out using SIMS. The depth profile in Figure 3 proposes that Li is mostly present between diamond and the $\mathrm{Cr}$ interlayer, indicating that the Li from the LNO substrates can diffuse through the Cr interlayer and be incorporated into the NCD films to a depth of about $90 \mathrm{~nm}$. The Li has thus been doped into the whole NCD film. O diffusion is also observed, but in a much lower level [27]. The presence of $\mathrm{Cr}$ at the interface region can lead to reactions with the carbon species in the growth plasma, forming chromium carbide [16,28-30], that can suppress the formation of amorphous carbon $(a-C)$, inducing the formation of diamond nuclei, and at the same time provide an enhanced bonding to the LNO substrate. The $\mathrm{Cr}$ interlayer interacts very well with both the NCD and LNO materials, not only improving the adhesion but also suppressing the diffusion of oxygen into the NCD films, while allowing the Li to diffuse through and be efficiently incorporated into the NCD films. Smith et al. [31] observed that Li atoms doped in the diamond films diffused markedly into the grain boundaries. Therefore, it is reasonable to assume that $\mathrm{Li}$ atoms are not doped inside the diamond grains but tend to aggregate or couple with other impurities in the NCD films. Restated, the diffused Li into the NCD films tend to reside at the grain boundaries, which can activate the formation of nanographitic phases, as like the case reported by Sankaran et al. [32], and thereby, forming conduction nanochannels that provide grain boundary transport. While such an assumption for the role of Li incorporation into NCD films on enhancing the conductivity of the materials sounds quite reasonable, further microstructural investigation using transmission electron microscopy is required to directly elucidate the formation of nanographitic phases at the grain boundaries due to Li doping.

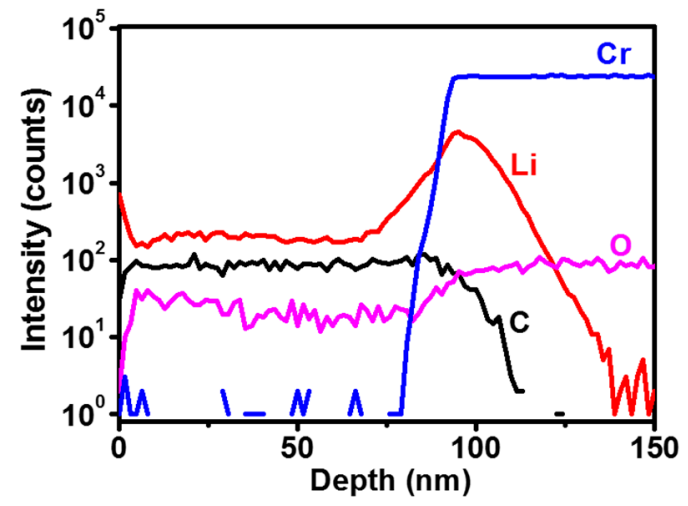

Figure 3. Secondary ion mass spectroscopy (SIMS) depth profiles of $\mathrm{C}$, $\mathrm{Li}, \mathrm{Cr}$, and $\mathrm{O}$ species in $\mathrm{NCD} / \mathrm{Cr} / \mathrm{LNO}$ films.

Consequently, the enhancement in the FEE properties of NCD/Cr/LNO is believed to be due to the use of a $\mathrm{Cr}$ interlayer and the Li-induced formation of nanographitic phases at the grain boundaries. The former increases the adhesion of the NCD films, while lowering the resistance for the transport of electrons across the interface region. The efficient Li incorporation increases markedly the bulk conductivity of the materials. Once the electrons can pass through the diamond-to-Cr/LNO interface, they can transport easily through the nanographitic phases induced along the grain boundaries of the films, to the emitting surface $[33,34]$.

Furthermore, to show the great potential of the NCD/Cr/LNO films for the device applications, an improved performance of a microplasma device using the NCD/Cr/LNO films as cathode is demonstrated. The detailed procedure for the fabrication of microplasma devices and the testing methodology for evaluation of the robustness of the cathode materials can be found in the supplementary information and Figure S5. Inset III of Figure 1 depicts a series of photographs of plasma devices at different applied voltages, showing that the microplasma using the NCD/Cr/LNO 
films as cathode can be triggered by a voltage of $310 \mathrm{~V}$. The intensity of the PI images increases monotonically with the applied voltage. This is better illustrated by the increase of the plasma current for NCD/Cr/LNO based microplasma devices reaching $615 \mu \mathrm{A}$ at an applied voltage of $550 \mathrm{~V}$ (Figure S5a). To evaluate the stability of the PI performance, the plasma current was monitored over a period of $150 \mathrm{~min}$ with a constant applied voltage of $350 \mathrm{~V}$. Figure S5b reveals that the plasma current of $133 \mu \mathrm{A}$ is upheld for a period of $143 \mathrm{~min}$, showing a high life-time stability for these microplasma devices. The better plasma performance using NCD/Cr/LNO films as cathode can be ascribed to the superior FEE properties of said films.

\section{Conclusions}

In summary, Li doping into NCD films grown at a low temperature of $350{ }^{\circ} \mathrm{C}$, using a $\mathrm{Cr}$ as interlayer, was accomplished via diffusion of Li from LNO substrates. The NCD/Cr/LNO films showed a low resistivity of $0.01 \Omega \cdot \mathrm{cm}$ and enhanced FEE properties, viz. a low turn-on field of $2.3 \mathrm{~V} / \mu \mathrm{m}$, a high FEE current density of $11.0 \mathrm{~mA} / \mathrm{cm}^{2}$ at $E=4.9 \mathrm{~V} / \mu \mathrm{m}$, a large field enhancement factor of 1670, and good life-time stability of $445 \mathrm{~min}$ at $J=3.0 \mathrm{~mA} / \mathrm{cm}^{2}$. Such an enhancement in the field emission behavior originates from the unique material combination: (i) the diffused Li atoms into the NCD films induced the formation of nanographitic phases along the grain boundaries, leading to better conductivity for these materials; and (ii) the $\mathrm{Cr}$ interlayer not only enriched the adherence of the NCD films on the LNO substrate but also efficiently improved the transport of electrons crossing the diamond-to-LNO interface. Both factors result in enhanced FEE properties of the NCD/Cr/LNO films. Additionally, the potential application of such films is demonstrated by the PI measurements, where a lowering of the threshold voltage to $310 \mathrm{~V}$ and increased life-time stability of $143 \mathrm{~min}$ at a plasma current of $133 \mu \mathrm{A}$, was observed. Consequently, the superior electrical conductivity and the enhanced FEE and PI characteristics render the low temperature deposited Li-doped NCD films a potential candidate for applications in flat panel displays and high brightness electron sources.

Supplementary Materials: The following are available online at http:/ www.mdpi.com/2079-4991/8/9/653/s1, Figure S1: (a) Field electron emission properties (current density-applied field, J-E, curves) measured in high vacuum environment with the inset showing the corresponding Fowler-Nordheim $(\mathrm{F}-\mathrm{N})$ plots and (b) shows the life-time stability measurements ( $J$-time curves) for I. NCD/Si and II. NCD/Cr/Si films, Figure S2: SEM micrographs of (a) NCD/Si and (b) NCD/Cr/Si thin films, Figure S3: The micro-Raman $(\lambda=488.0 \mathrm{~nm})$ spectra of (I) NCD/Si and (II) NCD/Cr/Si thin films, Figure S4: The XPS spectra of (a) NCD/Si, (b) NCD/Cr/Si, and (c) NCD/Cr/LNO thin films, Figure S5: (a) The plasma current - applied voltage curve, indicating the increase of plasma current with the applied voltage. (b) The plasma life-time measurements: the plasma emission current versus time, of a microplasma device, which utilized ITO coated glass as anode and using NCD/Cr/LNO films as cathode material.

Author Contributions: Conceptualization, K.J.S. and K.H.; Methodology, K.J.S. and K.H.; Investigation, K.J.S., P.-Y.H., K.P. and P.P.; Resources, K.H., J.Y.P., M.K.V.B. and N.-H.T.; Data Curation, K.J.S., K.P. and I.N.L.; Writing-Original Draft Preparation, K.J.S.; Writing-Review \& Editing, K.J.S., I.-N.L. and K.H.; Supervision, K.H.; Project Administration, K.J.S. and K.H.; Funding Acquisition, K.J.S. and K.H.

Funding: The authors like to thank the financial support of the Research Foundation Flanders (FWO) via Research Grants 12I8416N and 1519817N, and the Methusalem "NANO" network.

Acknowledgments: K. Panda and J. Y. Park acknowledge the Institute for Basic Science, S. Korea. The Hercules Foundation Flanders is acknowledged for financial support of the Raman equipment. K. J. Sankaran and P. Pobedinskas are Postdoctoral Fellows of the Research Foundation-Flanders (FWO).

Conflicts of Interest: The authors declare no conflict of interest.

\section{References}

1. Chubenko, O.; Baturin, S.S.; Kovi, K.K.; Sumant, A.V.; Baryshev, S.V. Locally resolved electron emission area and unified view of field emission from ultrananocrystalline diamond films. ACS Appl. Mater. Interfaces 2017, 9, 33229-33237. [CrossRef] [PubMed]

2. Terranova, M.L.; Orlanducci, S.; Rossi, M.; Tamburri, E. Nanodiamonds for field emission: State of the art. Nanoscale 2015, 7, 5094-5114. [CrossRef] [PubMed] 
3. Sankaran, K.J.; Ficek, M.; Kunuku, S.; Panda, K.; Yeh, C.J.; Park, J.Y.; Sawczak, M.; Michałowski, P.P.; Leou, K.C.; Bogdanowicz, R.; et al. Self-organized multi-layered graphene-boron doped diamond hybrid nanowalls for high performance electron emission devices. Nanoscale 2018, 10, 1345-1355. [CrossRef] [PubMed]

4. Sankaran, K.J.; Kurian, J.; Chen, H.C.; Dong, C.L.; Lee, C.Y.; Tai, N.H.; Lin, I.N. Origin of a needle-like granular structure for ultrananocrystalline diamond films grown in a $\mathrm{N}_{2} / \mathrm{CH}_{4}$ plasma. J. Phys. D Appl. Phys. 2012, 45, 365303. [CrossRef]

5. Janssen, W.; Turner, S.; Sakr, G.; Jomard, F.; Barjon, J.; Degutis, G.; Lu, Y.G.; D’Haen, J.; Hardy, A.; Van Bael, M.; et al. Substitutional phosphorus incorporation in nanocrystalline CVD diamond thin films. Phys. Status Solidi RRL 2014, 8, 705-709. [CrossRef]

6. Saravanan, A.; Huang, B.R.; Sankaran, K.J.; Tai, N.H.; Lin, I.N. Highly conductive diamond-graphite nanohybrid films with enhanced electron field emission and microplasma illumination properties. ACS Appl. Mater. Interfaces 2015, 7, 14035-14042. [CrossRef] [PubMed]

7. Bernholc, J.; Kajihara, S.A.; Wang, C.; Antonelli, A.; Davis, R.F. Theory of native defects, doping and diffusion in diamond and silicon carbide. Mater. Sci. Eng. B 1992, 11, 265-272. [CrossRef]

8. Khmelnitsky, R.A.; Saraykin, V.V.; Dravin, V.A.; Zavedeyev, E.V.; Makarov, S.V.; Bronsky, V.S.; Gippius, A.A. Lithium implanted into diamond: Regular trends and anomalies. Surf. Coat. Tech. 2016, 307, $236-242$. [CrossRef]

9. O’Donnell, K.M.; Martin, T.L.; Edmonds, M.T.; Tadich, A.; Thomsen, L.; Ristein, J.; Pakes, C.I.; Fox, N.A.; Ley, L. Photoelectron emission from lithiated diamond. Phys. Status Solidi A 2014, 211, 2209-2222. [CrossRef]

10. Te Nijenhuis, J.; Cao, G.Z.; Smits, P.C.H.J.; van Enkevort, W.J.P.; Giling, L.J.; Alkemade, P.F.A.; Nesladek, M.; Remes, Z. Incorporation of lithium in single crystal diamond: Diffusion profiles and optical and electrical properties. Diam. Relat. Mater. 1997, 6, 1726-1732. [CrossRef]

11. Uzan-Saguy, C.; Cytermann, C.; Fizgeer, B.; Richter, V.; Brener, R.; Kalish, R. Diffusion of lithium in diamond. Phys. Status Solidi A 2002, 193, 508-516. [CrossRef]

12. Othman, M.Z.; May, P.W.; Fox, N.A.; Heard, P.J. Incorporation of lithium and nitrogen into CVD diamond thin films. Diam. Relat. Mater. 2014, 44, 1-7. [CrossRef]

13. Halliwell, S.C.; May, P.W.; Fox, N.A.; Othman, M.Z. Investigations of the co-doping of boron and lithium into CVD diamond thin films. Diam. Relat. Mater. 2017, 76, 115-122. [CrossRef]

14. Sankaran, K.J.; Srinivasu, K.; Yeh, C.J.; Thomas, J.P.; Drijkoningen, S.; Pobedinskas, P.; Sundaravel, B.; Leou, K.C.; Leung, K.T.; Van Bael, M.K.; et al. Field electron emission enhancement in lithium implanted and annealed nitrogen incorporated nanocrystalline diamond films. Appl. Phys. Lett. 2017, 110, 261602. [CrossRef]

15. Joseph, P.T.; Tai, N.H.; Lin, I.N. Monolithic n-type conductivity on low temperature grown freestanding ultrananocrystalline diamond films. Appl. Phys. Lett. 2010, 97, 042107. [CrossRef]

16. Degutis, G.; Pobedinskas, P.; Turner, S.; Lu, Y.G.; Al Riyami, S.; Ruttens, B.; Yoshitake, T.; Haen, J.D.; Haenen, K.; Verbeeck, J.; et al. CVD diamond growth from nanodiamond seeds buried under a thin chromium layer. Diam. Relat. Mater. 2016, 64, 163-168. [CrossRef]

17. Drijkoningen, S.; Pobedinskas, P.; Korneychuk, S.; Momot, A.; Balasubramaniam, Y.; Van Bael, M.K.; Turner, S.; Verbeeck, J.; Nesladek, M.; Haenen, K. On the origin of diamond plates deposited at low temperature. Cryst. Growth Des. 2017, 17, 4306-4314. [CrossRef]

18. Fowler, R.H.; Nordheim, L. Electron emission in intense electric fields. Proc. R. Soc. Lond. Ser. A 1928, 119, 173-181. [CrossRef]

19. Urban, F.; Passacantando, M.; Giubileo, F.; Iemmo, L.; Bartolomeo, A.D. Transport and field emission properties of $\mathrm{MoS}_{2}$ bilayers. Nanomaterials 2018, 8, 151. [CrossRef] [PubMed]

20. Smith, R.C.; Cox, D.C.; Silva, S.R.P. Electron field emission from a single carbon nanotube: Effects of anode location. Appl. Phys. Lett. 2005, 87, 103112. [CrossRef]

21. Mapelli, C.; Castiglioni, C.; Zerbi, G.; Mullen, K. Common force field for graphite and polycyclic aromatic hydrocarbons. Phys. Rev. B 1999, 60, 12710. [CrossRef]

22. Ferrari, A.C.; Robertson, J. Origin of the $1150 \mathrm{~cm}^{-1}$ Raman mode in nanocrystalline diamond. Phys. Rev. B Condens. Matter Mater. Phys. 2001, 63, 121405. [CrossRef]

23. Ilie, A.; Ferrari, A.C.; Yagi, T.; Rodil, S.E.; Robertson, J.; Barborini, E.; Milani, P. Role of sp2 phase in field emission from nanostructured carbons. J. Appl. Phys. 2001, 90, 2024-2032. [CrossRef] 
24. Cancado, L.G.; Takai, K.; Enoki, T. General equation for the determination of the crystallite size $\mathrm{L}_{\mathrm{a}}$ of nanographite by Raman spectroscopy. Appl. Phys. Lett. 2006, 88, 163106. [CrossRef]

25. Ferrari, A.C.; Robertson, J. Interpretation of Raman spectra of disordered and amorphous carbon. Phys. Rev. B 2000, 61, 14095-14107. [CrossRef]

26. Joseph, P.T.; Tai, N.H.; Lee, C.Y.; Niu, H.; Pong, W.F.; Lin, I.N. Field emission enhancement in nitrogen-ion-implanted ultrananocrystalline diamond films. J. Appl. Phys. 2008, 103, 043720. [CrossRef]

27. Hu, X.J.; Ye, J.S.; Liu, H.J.; Shen, Y.G.; Chen, X.H.; Hu, H. n-type conductivity and phase transition in ultrananocrystalline diamond films by oxygen ion implantation and annealing. J. Appl. Phys. 2011, 109, 053524. [CrossRef]

28. Corbella, C.; Oncins, G.; Gomez, M.A.; Polo, M.C.; Pascual, E.; Cespedes, J.G.; Andujar, J.L.; Bertran, E. Structure of diamond-like carbon films containing transition metals deposited by reactive magnetron sputtering. Diam. Relat. Mater. 2005, 14, 1103-1107. [CrossRef]

29. Khun, N.W.; Liu, E.; Yang, G.C.; Ma, W.G.; Jiang, S.P. Structure and corrosion behavior of platinum/ruthenium/nitrogen doped diamond like carbon thin films. J. Appl. Phys. 2009, 106, 013506. [CrossRef]

30. Pleskov, Y.V.; Evstefeva, Y.E.; Baranov, A.M. Threshold effect of admixtures of platinum on the electrochemical activity of amorphous diamond-like carbon thin films. Diam. Relat. Mater. 2002, 11, 1518-1522. [CrossRef]

31. Smith, S.P.; Landstrass, M.I.; Wilson, R.G.; Benninghoven, A.; Janssen, K.T.F.; Tumpner, J.; Werner, H.W. Secondary Ion Mass Spectrometry, SIMS VIII, 8rd ed.; Wiley: New York, NY, USA, 1992; p. 159.

32. Sankaran, K.J.; Yeh, C.J.; Kunuku, S.; Thomas, J.P.; Pobedinskas, P.; Drijkoningen, S.; Sundaravel, B.; Leou, K.C.; Leung, K.T.; Van Bael, M.K.; et al. Microstructural Effect on the Enhancement of Field Electron Emission Properties of Nanocrystalline Diamond Films by Li-Ion Implantation and Annealing Processes. ACS Omega 2018, in press.

33. Yamaguchi, H.; Masuzawa, T.; Nozue, S.; Kudo, Y.; Saito, I.; Koe, J.; Kudo, M.; Yamada, T.; Takakuwa, Y.; Okano, K. Electron emission from conduction band of diamond with negative electron affinity. Phys. Rev. B 2009, 80, 165321. [CrossRef]

34. Geis, M.W.; Deneault, S.; Krohn, K.E.; Marchant, M.; Lyszczarz, T.M.; Cooke, D.L. Field emission at $10 \mathrm{~V} \mathrm{~cm}^{-1}$ with surface emission cathodes on negative-electron-affinity insulators. Appl. Phys. Lett. 2005, 87, 192115. [CrossRef] 